\title{
Potential effect of enclosure size on field experiments with herbivorous intertidal gastropods
}

\author{
G. P. Quinn, Michael J. Keough \\ Department of Ecology and Evolutionary Biology, Monash University, Clayton, Victoria 3168, Australia \\ and \\ Department of Zoology, University of Melbourne, Parkville, Victoria 3152, Australia
}

\begin{abstract}
Many experimental studies on the ecology of benthic marine herbivores, particularly those on intra- and inter-specific competition, have used enclosures to manipulate animal densities. We examined a potential problem in the interpretation of these experiments, i.e. the effects of different enclosure sizes on mortality and body weights of a rocky intertidal limpet fenced at natural densities. There was no mortality during the experiment but body weights of limpets were significantly different between fence sizes varying 4 fold. Interpretations of enclosure experiments generally, and comparisons of the magnitude of treatment effects in competition experiments specifically, may be equivocal if enclosure sizes are different.
\end{abstract}

Experimental studies on the ecology of intertidal gastropods have commonly used artificial enclosures (cages and/or fences) to exclude and enclose animals, thereby manipulating densities. In particular, intraand inter-specific competitive interactions between herbivorous gastropods have been assessed by such manipulations within enclosures (Branch 1984, Underwood 1985). In southeastern Australia, the common large limpet Cellana tramoserica has been used in numerous field experiments manipulating its densities on different shores and in a number of years; these experiments have consistently demonstrated that $C$. tramoserica is very susceptible to increased mortality and reduced body weights at high densities (Underwood 1978, Creese \& Underwood 1982, Parry 1982, Fletcher 1984, Underwood 1984, Fletcher \& Creese 1985). Underwood (1984) showed that reduced body weights of this species were directly correlated with available microalgae. Although the presence of competitive effects in each of these studies was unequivocal, comparisons of the magnitude of any treatment effects (i.e. changes in mortality or body weight) between studies is always difficult because of seasonal, geographical and other differences. Such comparisons are now being attempted, however, particularly as the approach of meta-analysis, which includes identifying effect sizes in different experiments, becomes more generally accepted (Gurevitch et al. 1992).

Difficulties in interpreting field experiments where densities of herbivorous intertidal gastropods are manipulated, due to cage or fence effects, have been considered. With Cellana tramoserica, for example, Underwood (1978) found no difference in weight between limpets enclosed at average densities and non-enclosed limpets. Parry (1982) found C. tramoserica climbing on top of each other to form stacks of up to 10 limpets in cages with high densities, a phenomenon rarely seen in uncaged limpets. Underwood (1984) reported that chlorophyll a concentrations (as a measure of food availability) outside cages were within the range of values inside cages with control densities of C. tramoserica. He also pointed out that comparisons between inside and outside enclosures were confounded by the different and uncontrolled densities and mixtures of grazers outside his cages. This confounding will apply to any comparison of animals or food availability inside and outside enclosures as a check for 'caging' effects. In this study, we identify another factor that can influence the interpretation of enclosure experiments on herbivorous gastropods but which has not been previously considered - the size of the experimental enclosures. For example, the size of the enclosures used in previous experiments on C. tramoserica varied considerably, with the maximum linear dimension ranging from $20 \mathrm{~cm}$ (Creese 
\& Underwood 1982) to $40 \mathrm{~cm}$ (Parry 1982), although Fletcher (1984) used unfenced areas of $50 \mathrm{~cm}^{2}$.

Materials and methods. We report here the results of a simple experiment to test for effects of enclosure size on mortality and body weights of Cellana tramoserica. The study site was the exposed rocky shore at Cheviot Beach, inside Point Nepean National Park, at the entrance to Port Phillip Bay, Victoria, Australia (Povey \& Keough 1991). Plastic mesh fences (mesh size $1 \mathrm{~cm}$ ) were used as enclosures. These fences had walls $10 \mathrm{~cm}$ high, with a horizontal flange folding outward from the base. Strips of medium density foam rubber $13 \mathrm{~cm}$ wide) were placed on these flanges, followed by a $2 \mathrm{~cm}$ wide strip of PVC. These strips were screwed into plastic plugs inserted into the rock, using stainless steel screws. The resulting compression of the foam-filled gaps between the fence material and the rock surface prevented movement of limpets in and out of fenced areas. Because the foam was quite porous and highly compressed, there was no retention of water within the fences at low tide and the rock surfaces within enclosures appeared to dry at similar times as those of nearby unfenced rock.

Limpets (shell length 20 to $25 \mathrm{~cm}$ ) were enclosed at natural densities in fences of 3 different sizes (based on the 'standard' fence size used in other experiments with this species at this site; authors' unpubl. data): 1 limpet per $306 \mathrm{~cm}^{2}$ fence (quarter size), 4 limpets per $1225 \mathrm{~cm}^{2}$ fence (standard size) and 16 limpets per $4900 \mathrm{~cm}^{2}$ fence (4-times size). The limpets were collected, and then assigned randomly to fences. There were 5 replicate fences of each size. The experiment started on 11 February 1992, and missing limpets were replaced with marked individuals of similar size at fortnightly intervals. On 13 April 1992, all original limpets from the 2 smaller fence sizes, and a subsample of 5 original limpets from the each of the large fences, were collected, their shell lengths measured to the nearest $\mathrm{mm}$, and their soft tissue dried at $50^{\circ} \mathrm{C}$ and weighed.

We estimated the amount of available food for the limpets by collecting 2 rock chips, each ca $1 \mathrm{~cm}^{2}$, from the rock surface within each fence, and 5 chips haphazardly from outside the fences. Total chlorophyll a was determined using the hot methanol extraction method recommended by Hill \& Hawkins (1990). These values were converted to chlorophyll a concentrations by digitizing the rock chips to determine their area, and using this area to standardize the chlorophyll values as $\mu \mathrm{g} \mathrm{cm}^{-2}$

Results and discussion. There was no mortality of limpets in any fence size during the experiment. Shell lengths and dry tissue weights of limpets from the different fence sizes were compared by analyses of variance; boxplots and plots of residuals revealed no major violations of the assumptions of normality and homo-
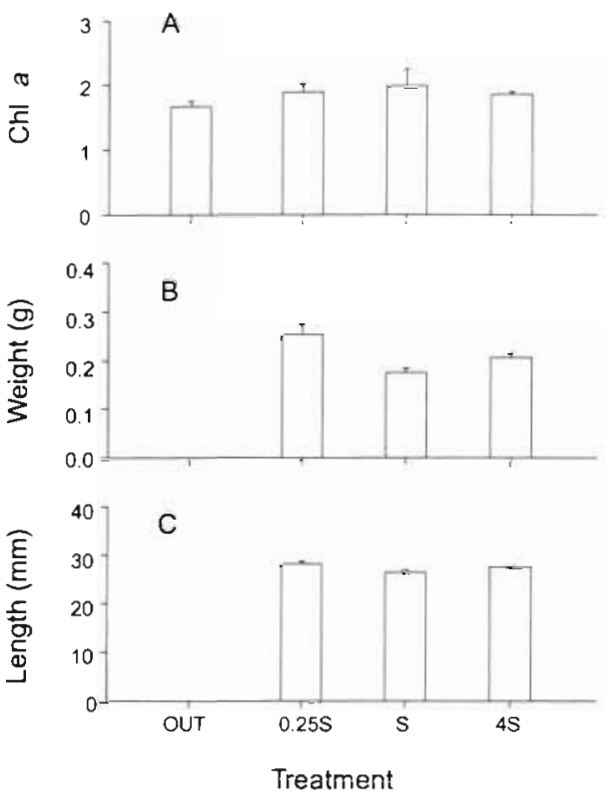

Fig. 1. Cellana tramoserica. Mean (+SE) values for (A) chlorophyll concentrations from rock scrapings, and (B) dry body weights and $(\mathrm{C})$ shell lengths of limpets from different experimental treatments. $S$ refers to standard $1225 \mathrm{~cm}^{2}$ fence size and OUT refers to outside fences

geneity of variance. Variation between fences could only be tested for the 2 larger sizes because only 1 limpet was present in each of the smallest fences. There were no significant differences for either shell lengths or dry tissue weights between fences within each of the 2 larger fence sizes $(p>0.25)$ so data from the fences within these 2 fence sizes were pooled for comparison with the smallest fence size. There were no significant differences in shell lengths $\left(F_{2,47}=2.78, \mathrm{p}=\right.$ 0.072 ) but there were significant differences between dry tissue weights of limpets from the different fence sizes $\left(F_{2,47}=4,85, \mathrm{p}=0.012\right)$. The greatest body weight occurred in the smallest fence size (Fig. 1), although an SNK test only separated the standard and the quarter fence sizes, with limpets from the 4-times fence size intermediate in body weight. An analysis of covariance showed that length-specific weights were also significantly different between fence sizes (ANCOVA, $F_{2,46}=$ $3.81, p=0.03 ;$ slopes not significantly heterogeneous, $p$ $>0.25$ ), with the adjusted mean weights showing the same pattern as unadjusted weights. None of these differences in body weight were related to food availability in the fences, as there were no significant differences in chlorophyll a concentrations between fence sizes or outside the fences $\left(F_{3,15}=0.58, p=0.637\right)$.

These experiments did not test for any interaction between enclosure size and density effects, and any dependence of the intensity of competition on enclosure size cannot be estimated; it is clear, however, that 
the size of enclosures can affect body weights of limpets at a specific density. Although body weights were not related to fence size in a simple manner (Fig. 1), the greater body weight in the smallest fences may be due to these fences being most likely to retain moisture, and having proportionally the largest area shaded, both of which could increase growth of microalgae. There were, however, no significant variations in chlorophyll concentrations between the different fence sizes, although these measurements confound any fence size effect with possible differential grazing rates of limpets in different sized fences. If limpets actually consume all the extra microalgae available in the small fences, increased microalgal growth would not result in any change in standing crops.

Populations of Cellana tramoserica can include both homing and non-homing individuals (Underwood 1977). Although the distances moved by homing $C$. tramoserica during a feeding excursion are not known because they move primarily at high tide, Underwood (1977) and Mackay \& Underwood (1977) found nonhoming limpets in New South Wales could move linear distances of between about 21 and $42 \mathrm{~cm} \mathrm{~d}^{-1}$ Limpets in an intertidal boulder field at Williamstown, Victoria, also moved $>50 \mathrm{~cm}$ during high tide ( $\mathrm{M}$. Keough \& R. Bathgate unpubl. obs.). These distances are greater than the diagonals of the small and intermediate fences in this study. However, any negative effects of restricted movement should be more pronounced in small fences, whereas we found the opposite result. Data on rates and actual distances moved inside enclosures would be required before the apparent positive effect in small fences can be explained unequivocally.

Although the effect of enclosure size on Cellana tramoserica was only on body weight and not mortality, our results suggest that comparisons of the magnitude of treatment effects in experiments using different enclosure sizes should be made with some caution.

This note was submitted to the editor
Acknowledgements. We thank Nick Otway for discussions of the original idea and M. Shirley and J. Radford for assistance in the field. This study was supported by the Australian Research Council.

\section{LITERATURE CITED}

Branch, G. M. (1984). Competition between manne organisms: ecological and evolutionary implications. Oceanogr. mar. Biol. A. Rev. 22: 429-593

Creese, R. G., Underwood, A. J. (1982). Analysis of inter- and intra-specific competition amongst intertidal limpets with different methods of feeding. Oecologia 53: $337-346$

Fletcher, W. J. (1984). Intraspecific variation in the population dynamics and growth of the limpet, Cellana tramoserica. Oecologia 63: 110-121

Fletcher, W. J., Creese, R. G. (1985). Competitive interactions between co-occurring herbivorous gastropods. Mar. Biol. 86: 183-191

Gurevitch, J., Morrow, L. L., Wallace, A., Walsh, J. S. (1992). A meta-analysis of competition in field experiments. Am. Nat. 140:539-572

Hill, A. S., Hawkins, S. J. (1990). An investigation of methods for sampling microbial films on rocky shores, J. mar. biol. Ass. U.K. 70: 77-88

Mackay, D. A., Underwood, A. J. (1977). Experimental studies on homing in the intertidal patellate limpet Cellana tramoserica (Sowerby). Oecologia 30: 216-238

Parry, G. D. (1982). The evolution of the life histories of four species of intertidal limpets. Ecol. Monogr. 52: 65-91

Povey, A., Keough, M. J. (1991). Effects of trampling on plant and animal populations on rocky shores. Oikos 61: $355-368$

Underwood, A. J. (1977). Movements of intertidal gastropods. J. exp. mar. Biol. Ecol. 26: 191-201

Underwood, A. J. (1978). An experimental evaluation of competition between three species of intertidal prosobranch gastropods. Oecologia 33: 185-202

Underwood, A. J. (1984). Vertical and seasonal patterns in competition for microalgae between intertidal gastropods. Oecologia 64: 211-222

Underwood, A. J. (1985). Physical factors and biological interactions: the necessity and nature ecological experiments. In: Moore, P. G., Seed, R. (eds.) The ecology of rocky coasts. Hodder \& Stoughton, London, p. 372-390

Manuscript first received: October 20,1992

Revised version accepted: April 1, 1993 